\title{
PERUMUSAN KONSEP IDENTITAS KABUPATEN SIDOARJO UNTUK CITY BRANDING MELALUI PENDEKATAN COMPETITIVE IDENTITY
}

\author{
R. Bhima Danniswara ${ }^{1}$, Agung Eko Budiwaspada ${ }^{2}$, Naomi Haswanto ${ }^{3}$ \\ Program Studi Magister Desain - Fakultas Seni Rupa dan Desain, Institut Teknologi Bandung \\ Email: bhimadanniswara@gmail.com.
}

\begin{abstract}
Identity is an important aspect in the formation of a city branding. The identity that is used as a basis in the formation of city branding must be unique compared to other cities. A positive city identity will reflect a positive city image in the minds of the audience. Formulation of city identity can be done by applying competitive identity theory to communicate positive messages to be conveyed to the audience, through the six channels of city identity. The ideal city identity must be formulated based on the facts that occur in the city itself. Result of this research is "connectedness" as representative identity for Sidoarjo. "Connectedness" can be used as a basis for Sidoarjo city branding design.
\end{abstract}

Key Words: city branding Sidoarjo, competitive identity, brand identity

\begin{abstract}
Abstrak: Identitas merupakan aspek penting dalam pembentukan sebuah city branding. Identitas yang dijadikan sebuah dasar dalam pembentukan city branding haruslah memiliki keunikan dibandingkan kota lain. Identitas kota yang positif akan mencerminkan image kota yang positif pula di benak audien. Perumusan identitas kota dapat dilakukan dengan menerapkan teori competitive identity untuk mengkomunikasikan pesan positif yang ingin disampaikan ke khalayak sasaran, melalui keenam kanal identitas kota. Identitas kota yang ideal harus dirumuskan berdasarkan fakta yang terjadi di kota bersangkutan. Hasil yang didapatkan dari penelitian ini adalah "keterhubungan" sebagai identitas yang representatif bagi Sidoarjo. "Keterhubungan" tersebut bisa digunakan sebagai dasar perancangan city branding bagi Sidoarjo.
\end{abstract}

Kata kunci: city branding Sidoarjo, competitive identity, brand identity

Sidoarjo merupakan salah satu wilayah yang berada di Provinsi Jawa Timur. Berdampingan dengan Kota Surabaya, Kabupaten Mojokerto. Kabupaten Pasuruan, dan Kabupaten Gresik, Sidoarjo menjadi salah satu poros penting dalam kelangsungan perekonomian Provinsi Jawa Timur. Ini dikarenakan letak geografis Sidoarjo yang berada di tengah-tengah dari wilayah industri lain. Kondisi tersebut menjadikan Sidoarjo sebagai jalur produksi dan distribusi industri yang penting dari wilayah di sekitarnya, sebelum diteruskan untuk diekspor melalui Pelabuhan Tanjung Perak di Kota Surabaya.

Di balik prestasi sektor industrinya, pembahasan tentang Sidoarjo pada kurun waktu 2010 hingga 2019 tidak bisa dilepaskan dari tragedi semburan lumpur. Tragedi tersebut dimulai pada bulan Mei tahun 2006, yang lebih dikenal dengan Lumpur Lapindo atau Lumpur Sidoarjo. Selama 13 tahun, bencana semburan
Lumpur Sidoarjo menimbulkan kerugian yang sangat besar bagi perekonomian Provinsi Jawa Timur, mengingat Sidoarjo merupakan salah satu poros industri yang menjadi ujung tombak perekonomian Jawa Timur. Menilik berita yang dirilis oleh portal berita IDN Times pada 28 Mei 2016, bencana Lumpur Sidoarjo menimbulkan dampak buruk yang sangat besar pada berbagai sektor, seperti lumpuhnya akses jalan tol Sidoarjo - Gempol dan penarikan investasi besar-besaran oleh perusahaan asing (https://www. idntimes.com/news/indonesia/amp/erwanto/pe rubahan-yang-terjadi-setelah-10-tahunlapindo).

Terhitung hingga tahun 2019, kerugian yang ditimbulkan semakin menyebar pada sektor yang lebih luas, mengutip infografis yang diterbitkan oleh CNN Indonesia pada 11 Juli 2019, Lumpur Sidoarjo telah menghilangkan lapangan pekerjaan bagi 1.873 warga Sidoarjo, 


\section{R. Bhima Danniswara, Agung Eko Budiwaspada, Naomi Haswanto PERUMUSAN KONSEP IDENTITAS KABUPATEN SIDOARJO UNTUK CITY BRANDING MELALUI PENDEKATAN COMPETITIVE IDENTITY}

serta mengakibatkan kerugian ekonomi secara langsung dan tak langsung sebesar 27,5 triliun rupiah bagi pemerintah. Selain kerugian bagi pemerintah, sebanyak 40 ribu jiwa juga menderita karena kehilangan tempat tinggal akibat terendam lumpur (https://m.cnnindonesia.com/ekonomi/201907 09154427-95-410543/infografis-dampakekonomi-semburan-lumpur-lapindo).

Selain itu, dampak semburan lumpur juga mengakibatkan rusaknya sumber daya mencakup persawahan, kebun tebu, kebun hortikultura palawija, kolam, hewan-hewan ternak, areal pesisir serta kerugian nonekonomi yaitu kehilangan fungsi ekologis dan sosial budaya (Hidayat dkk., 2010). Citra Sidoarjo yang terdampak semburan lumpur tersebut menjadi pertimbangan investor untuk menanamkan modalnya di Sidoarjo. Hal ini dapat dilihat dari sedikitnya jumlah investasi di Sidoarjo yang hanya mencapai 1,7 triliun rupiah pada triwulan pertama di tahun 2019 . Jumlah tersebut hanya $10 \%$ dari target Pemerintah Sidoarjo pada tahun 2019, dengan total sebesar 17 triliun rupiah (https://www.jawapos.com/jpgtoday/27/05/2019/investasi-di-sidoarjo-barurp-17 -triliun/\%3famp).

Menguatkan pendapat bahwa citra mempunyai dampak pada sebuah keputusan untuk berinvestasi, menurut Kuncoro kegiatan investasi pada suatu wilayah dapat didongkrak melalui beberapa cara, salah satunya adalah yang disebut sebagai image marketing, yaitu strategi yang mengandalkan image atau citra yang dimiliki orang akan suatu daerah agar menanamkan investasi di daerah tersebut (Kuncoro, 2004). Hal tersebut mengimplikasikan bahwa kegiatan investasi di Sidoarjo yang turun bisa dipengaruhi oleh image Sidoarjo yang terkena tragedi semburan lumpur.

Maka dari itu dalam konteks problematika Sidoarjo, investasi, dan bencana semburan lumpur ini, diperlukan sebuah cara untuk merumuskan identitas Sidoarjo secara komprehensif guna mendukung program city branding Sidoarjo dalam menanggapi permasalahan citra yang terjadi di Sidoarjo. Hal tersebut diproyeksikan untuk bisa meningkatkan jumlah investasi ke Sidoarjo di masa mendatang.

\section{METODE}

Semua data yang diperoleh dari wawancara, kuisioner, serta observasi akan dikerucutkan menggunakan pola berpikir reflektif dan kreatif. Data tersebut kemudian diulas menggunakan metode competitive identity yang dikemukakan oleh Anholt, hingga didapatkan identitas Sidoarjo. Anholt dalam teorinya yaitu competitive identity menjabarkan identitas dapat dibentuk dengan cara sebagai berikut, sebuah negara membentuk reputasinya melalui gagasan yang disampaikan melalui enam kanal, antara lain promosi kepariwisataan, produk (brand) yang diekspor, kebijakan pemerintah, penggiat bisnis (investor), kebudayaan, dan warga lokal (Anholt, 2007). Untuk lebih jelasnya dapat dilihat pada diagram sebagai berikut.

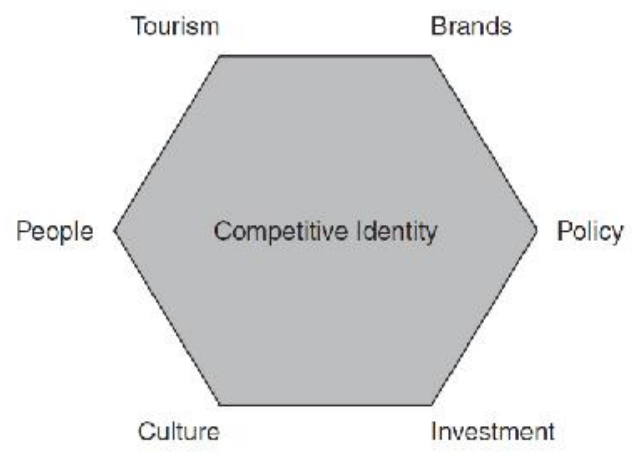

Gambar 1. Heksagon competitive identity (Anholt, 2007)

Dapat dilihat pada diagram di atas, bahwa identitas sebuah tempat, dalam hal ini identitas suatu kota dapat dibentuk melalui ide inti brand yang dikomunikasikan melalui kanal yang telah disebutkan. Penggunaan kata "dikomunikasikan" pada konteks ini adalah sebuah pencerminan, sebagai contoh ketika "ramah lingkungan" menjadi ide inti brand Kota A, maka keenam kanal yang dimiliki oleh Kota A ini harus secara kontinyu mencerminkan aspek "ramah lingkungan" tersebut. Menurut Anholt, dari keenam kanal competitive identity, terdapat beberapa kanal yang efektif digunakan sebagai media untuk menyampaikan branding suatu kota, yaitu 
kanal tourism, brands, dan culture. Tiga kanal tersebut memiliki kekuatan yang besar, karena selain menguntungkan bagi kota yang bersangkutan, ketiga kanal tersebut merupakan kanal yang secara langsung berhubungan dengan pihak eksternal (Anholt, 2007).

\section{PAPARAN DATA}

Sidoarjo merupakan daerah dengan keberagaman etnis yang tinggi didominasi oleh etnis jawa, sedangkan etnis arab, madura, hingga tionghoa hidup berdampingan dan tersebar di seluruh wilayahnya. Pemerintah Kabupaten Sidoarjo melalui situs resminya, menyatakan bahwa pertambahan penduduk Sidoarjo yang cepat bukan dikarenakan tingginya angka kelahiran, melainkan karena arus urbanisasi. Perkembangan penduduk Sidoarjo banyak terjadi di wilayah perbatasannya dengan Kota Surabaya dan Kabupaten Gresik. Mengingat kedua wilayah tersebut merupakan daerah yang sibuk, Kota Surabaya sebagai Ibukota Provinsi Jawa Timur, kota metropolitan terbesar kedua setelah Jakarta, dan juga sekaligus terkenal akan image-nya sebagai kota perdagangan. Sedangkan Kabupaten Gresik merupakan daerah yang terkenal akan industrinya yang berskala besar. Selain daripada itu, wilayahwilayah tersebut juga memiliki infrastruktur seperti jalan raya yang cukup memadai sebagai sarana untuk mobilitas warga Sidoarjo yang bermukim di wilayah bersangkutan.

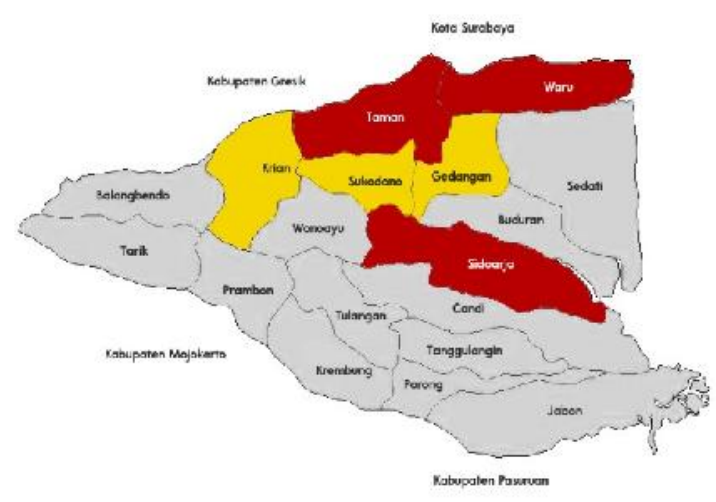

Gambar 2. Persebaran penduduk di wilayah Sidoarjo.

Membicarakan pariwisata yang ditawarkan oleh Sidoarjo, maka tidak akan bisa lepas terlalu jauh dari wisata kesejarahan dan kebudayaan setempat yang berakar sebelum masa keemasan Kerajaan Majapahit. Salah satunya adalah sebuah situs bersejarah Watu Tulis, atau sering disebut sebagai Candi Watu Tulis. Terletak di Kecamatan Prambon, Kabupaten Sidoarjo, merupakan sebuah candi dengan corak Hindu. Selain Candi Watu Tulis, juga terdapat candi-candi lain yang berdiri pada zaman Kerajaan Majapahit. Seperti Candi Pari, Candi Sumur, dan Candi Pamotan di Kecamatan Porong, Candi Dermo di Kecamatan Wonoayu, Candi Medalem di Kecamatan Tulangan, Candi Wangkal di Kecamatan Krembung, Candi Tawangalun di Kecamatan Sedati, dan Candi Terung di Kecamatan Krian. Selain wisata kesejarahan, Sidoarjo memiliki wahana wisata berupa kolam pemancingan, salah satunya adalah Kolam Pancing Delta Fishing. Terletak di Desa Prasung, Kecamatan Buduran, wahana wisata ini menghadirkan kolam pemancingan yang ramah terhadap keluarga. Selain beberapa kolam yang berisikan berbagai macam ikan, Delta Fishing juga menyajikan wisata outbond seperti flying fox dan kolam renang. Sektor lain yang juga menjadi salah satu unggulan Sidoarjo adalah transportasi, yang bisa dilihat sebagai penunjang pariwisata. Sidoarjo memiliki Bandara Internasional Juanda dan Terminal Purabaya sebagai pintu masuk wisatawan yang berkunjung ke berbagai wilayah di Jawa Timur.

Sidoarjo memiliki sebuah warisan budaya yang kental akan asal-usul kedaerahannya, yaitu Batik Sidoarjo. Dilihat dari segi warna, Batik Sidoarjo kental akan ciri khas batik pesisir yang didominasi oleh warna-warna cerah. Hingga masa kini, beberapa komunitas pembatik mulai punah, karena tidak bisa memenuhi permintaan pasar dan tidak ada yang mewariskan keahliannya. Salah satu komunitas batik tulis yang masih bertahan di Sidoarjo adalah Komunitas Batik Jetis yang berada di Kampung Jetis, Kecamatan Sidoarjo. Batik Sidoarjo ini memiliki ciri khas yang unik, karena memiliki pengaruh dari berbagai kebudayaan, baik jawa, madura, arab, hingga tionghoa.

Sidoarjo juga terkenal dengan sektor perikanannya, dengan komoditas udang dan ikan bandeng, baik sebagai produk mentah ataupun sebagai produk yang sudah diolah 


\section{R. Bhima Danniswara, Agung Eko Budiwaspada, Naomi Haswanto PERUMUSAN KONSEP IDENTITAS KABUPATEN SIDOARJO UNTUK CITY BRANDING MELALUI PENDEKATAN COMPETITIVE IDENTITY}

menjadi kuliner khas Sidoarjo.

Tabel 1. Komoditas hasil perikanan Kabupaten Sidoarjo tahun 2016 (Sumber: BPS Sidoarjo 2017)

\begin{tabular}{|l|c|}
\hline Komoditas & Jumlah (dalam juta kg) \\
\hline Bandeng & 33,88 \\
\hline Ikan Nila & 13,3 \\
\hline Udang Windu & 3,61 \\
\hline Udang Vanamel & 5,96 \\
\hline Udang Campur & 3,6 \\
\hline Udang Lain & 3,1 \\
\hline Kepiting & 0,26 \\
\hline Ikan Lain & 1,65 \\
\hline Rumput Laut & 10,08 \\
\hline
\end{tabular}

Sidoarjo juga merupakan daerah yang terkenal dengan industri kecil menengah yang ditekuni oleh masyarakatnya. Sehingga pada pertengahan tahun 2018, Pemerintah Kabupaten Sidoarjo bekerjasama dengan BEKRAF mengadakan sebuah workshop kreatif bernama "Sidoarjo Workshop Creative Fest" yang dilaksanakan pada tanggal 28 Juni 2018 , bagi para pelaku industri kecil menengah untuk memajukan usahanya. Hal tersebut dapat dilihat sebagai salah satu perwujudan dari kebijakan Pemerintah Kabupaten Sidoarjo yang bertujuan untuk memajukan industri kecil menengah di Sidoarjo. Pada tahun 2015 Badan Pusat Statistik Jawa Timur mencatat 978 industri besar dan sedang berada di Sidoarjo. Angka ini merupakan angka tertinggi di Jawa Timur, mengungguli Surabaya, Gresik, dan Pasuruan. Menurut Pemerintah Kabupaten Sidoarjo melalui portal website-nya menyatakan bahwa industri merupakan salah satu sektor unggulan untuk menunjang perekonomian Sidoarjo. Lokasi Sidoarjo yang berdekatan dengan pusat perdagangan di Jawa Timur yaitu Kota Surabaya, dekat dengan pelabuhan Tanjung Perak dan Bandara Internasional Juanda sebagai titik distribusi penting bagi perdagangan berskala nasional maupun internasional merupakan magnet yang kuat bagi para investor untuk menanamkan modalnya di Sidoarjo.

Kemajuan sektor perikanan di Sidoarjo dapat ditarik mundur hingga pada zaman Kerajaan Jenggala, yang merupakan pecahan dari Kerajaan Kahuripan. Kerajaan Jenggala mengalami kemajuan ekonomi yang pesat karena menguasai wilayah perairan sebagai pusat perdagangan. Tipikal kerajaan maritim tersebut mempengaruhi masyarakat Sidoarjo yang 'dekat' dengan kelautan. Baik dari segi kebudayaan hingga mata pencaharian masyarakat setempat. Kedekatan masyarakat Sidoarjo dengan kelautan juga dapat dilihat pada Upacara Adat Nyadran yang dilakukan setiap bulan Ruwah saat bulan purnama. Nyadran merupakan upacara adat bagi para nelayan kupang di Desa Balongdowo, Kecamatan Candi, Kabupaten Sidoarjo. Prosesi Nyadran mulai dilakukan sejak malam hari dengan mengadakan ziarah dan kenduri di Makam Dewi Sekardadu dan berpuncak pada kegiatan peragaan mencari kupang di Selat Madura pada esok harinya. Upacara adat ini merupakan sebuah ungkapan syukur para nelayan terhadap hasil laut.

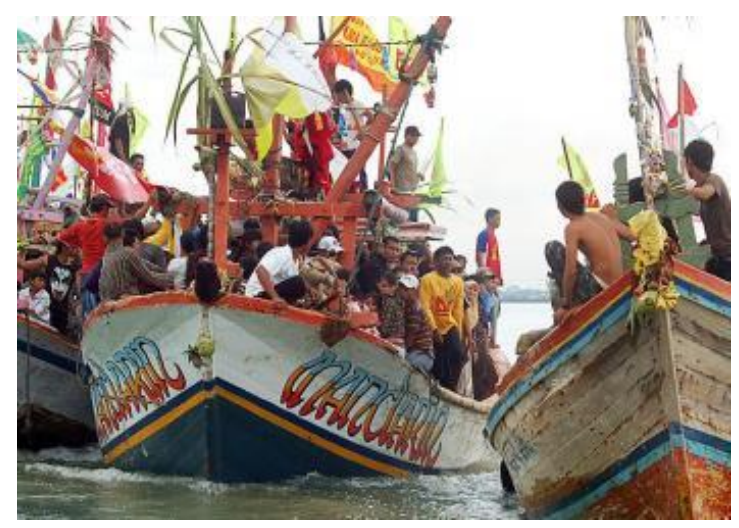

Gambar 3. Upacara Nyadram di Sidoarjo

Selain sebagai tempat berdagang dan pusat aktivitas kelautan bagi masyarakatnya, Kerajaan Jenggala juga menjadi tempat singgah atau transit kapal-kapal pedagang berskala internasional sehingga masyarakatnya memiliki keberagaman dari segi etnis. Mulai dari etnis arab hingga etnis tionghoa. Kehidupan dengan pluralisme tersebut pada akhirnya juga mempengaruhi kebudayaan masyarakat Sidoarjo, baik dari segi toleransi yang tinggi antar etnis, hingga produk kebudayaan yang dihasilkan oleh masyarakat. Dilihat dari segi kebudayaannya, Sidoarjo dapat dikatakan identik dengan Surabaya. Pada masyarakat Sidoarjo yang didominasi oleh etnis Jawa, kultur yang berkembang adalah Jawa Arek. Jawa Arek merupakan salah satu 
subkultur Jawa yang berkembang di sepanjang aliran Sungai Brantas dan pesisir, dengan ciri khas yang berbeda dengan kultur masyarakat Jawa pada umumnya yang hierarkis. Keberagaman yang tinggi dan kondisi alam yang keras di Sidoarjo menuntut masyarakatnya untuk selalu tanggap pada perubahan yang cepat dan mampu beradaptasi dalam bertahan hidup.

\section{ANALISIS}

Brand identity pada suatu kota merupakan seperangkat asosiasi unik yang melekat pada suatu kota, dan dapat dibentuk melalui enam kanal competitive identity (Anholt, 2007). Berdasar dari teori tersebut, konsep identitas Sidoarjo bisa dibentuk melalui profil penduduknya (people), kebudayaan yang berkembang di wilayahnya (culture), investasi yang dilakukan (investment), kebijakan pemerintah yang dikeluarkan (policy), produk yang dihasilkan (product), dan pariwisata yang ditawarkan (tourism).

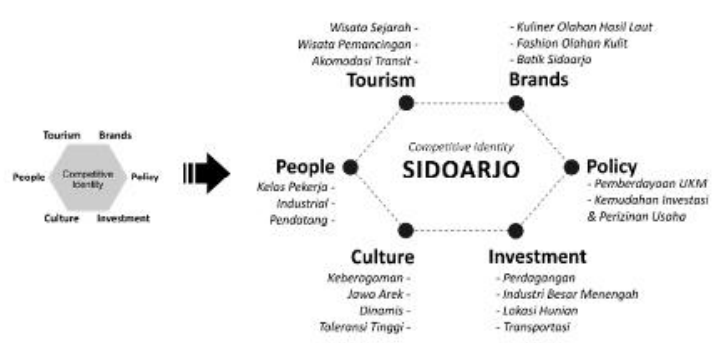

Gambar 4. Competitive identity versi Sidoarjo.

Berdasar dari gambaran competitive identity Sidoarjo di atas, bisa dilihat ada benang merah yang berpotensi untuk menjadi identitas Sidoarjo. Penjelasannya adalah sebagai berikut.

Sidoarjo merupakan daerah yang strategis dalam menghubungkan satu daerah dengan daerah lain. Hal ini dapat dilihat pada kanal masyarakat, pariwisata, produk, kebijakan pemerintah, investasi, dan kebudayaan Sidoarjo. Semua kanal tersebut adalah penghubung satu hal dengan yang lain, misalnya pada kanal masyarakat, Sidoarjo didominasi oleh penduduk yang bekerja di wilayah lain, mereka senantiasa terhubung antara kehidupan keluarga dan karirnya melalui Sidoarjo. Kesibukan berlalu-lalang setiap hari inilah yang bisa dilihat sebagai hal yang saling terhubung. Kanal berikutnya adalah kanal pariwisata. Wisata yang ditawarkan Sidoarjo kebanyakan merupakan wisata kesejarahan yang menghubungkan masa kini dengan masa lalu. Selain itu, fasilitas akomodasi yang ditawarkan oleh Sidoarjo kepada wisatawan lebih condong kepada fasilitas untuk transit untuk menuju tujuan sebenarnya, seperti akses pada Bandara Juanda dan Terminal Purabaya, maupun akomodasi lain seperti hotel dan restoran ataupun cafe. Begitu juga dengan wisata lain yang ditawarkan, yaitu pemancingan yang berorientasi kepada budaya masyarakat Sidoarjo yang sejak dahulu kala 'dekat' dengan perairan. Hal ini juga berlaku untuk kanal produk, yang mengandalkan produk mentah ataupun olahan dari udang dan bandeng sebagai komoditas andalan Sidoarjo.

Kanal berikutnya adalah kanal kebijakan publik yang diterapkan oleh Pemerintah Kabupaten Sidoarjo. Dalam konteks ini Pemerintah Kabupaten Sidoarjo menetapkan regulasi yang menghubungkan antara produsen dengan pasar, hal ini terlihat dari kebijakan yang mendukung kemajuan industri UKM. Selain itu, Pemerintah Kabupaten Sidoarjo juga mendukung terjadinya interaksi antara produsen UKM dengan investor, dengan membuka peluang investasi yang diusahakan melalui kerjasama dengan pemerintah pusat (BEKRAF).

Kemudian pada kanal investasi, transportasi dan pergudangan merupakan penopang dalam kegiatan perindustrian, lebih tepatnya pada aspek distribusi. Hal ini dapat dilihat dengan hadirnya lokasi pergudangan di Sidoarjo dari pabrik-pabrik yang bertempat di luar wilayah Sidoarjo. Pada kanal kebudayaan, telah disebutkan bahwa masyarakat Sidoarjo sangat beragam, namun mampu hidup secara berdampingan dan saling melengkapi. Tidak lain hal ini merupakan sebuah 'keterhubungan' yang baik antar satu etnis dengan etnis yang lainnya.

Maka setelah melalui proses berpikir reflektif dan kreatif, pada akhirnya ditemukan sebuah rumusan identitas konseptual bagi Sidoarjo, yaitu sebuah wilayah yang menghubungkan. 


\section{R. Bhima Danniswara, Agung Eko Budiwaspada, Naomi Haswanto PERUMUSAN KONSEP IDENTITAS KABUPATEN SIDOARJO UNTUK CITY BRANDING MELALUI PENDEKATAN COMPETITIVE IDENTITY}

Keterhubungan menjadi identitas yang representatif terhadap realita Sidoarjo. Selain itu, keterhubungan mampu mewakili keenam kanal identitas Sidoarjo yang telah dijabarkan sebelumnya.

\section{HASIL}

Melalui teori competitive identity, "keterhubungan" merupakan rumusan identitas yang representatif untuk Sidoarjo. Rumusan identitas tersebut juga tidak serta-merta muncul begitu saja, namun juga diwakili secara fisik. Hal ini dapat dilihat dari terhubungnya kembali ruas jalan tol Sidoarjo - Gempol, yang terkoneksi dengan jaringan jalan tol nasional Trans Jawa. Selain itu, Sidoarjo kini juga sudah kembali terhubung secara industri, dengan dibangunnya kompleks pergudangan dan industri yang baru, berlokasi di salah satu jalan lingkar di sisi timur Sidoarjo yang relatif jauh dari area terdampak semburan lumpur. Lebih daripada itu, konsep keterhubungan juga dirasa sangat sesuai sebagai antitesis terhadap citra Sidoarjo yang sempat "terputus" karena bencana semburan lumpur.

\section{KESIMPULAN}

Sidoarjo merupakan sebuah wilayah yang memiliki berbagai potensi untuk mengembangkan wilayahnya. Namun tragedi semburan lumpur menjadikan image Sidoarjo menjadi negatif. Untuk menimbulkan citra positif di wilayah Sidoarjo maka diperlukan sebuah rumusan identitas yang representatif dan berpotensi untuk dikembangkan sebagai dasar perancangan city branding.

Keterhubungan merupakan rumusan identitas yang representatif untuk Sidoarjo. Rumusan identitas tersebut mampu mewakili dari keenam kanal competitive identity versi Sidoarjo, dan berpotensi untuk digunakan sebagai acuan dalam merancang city branding bagi Sidoarjo.

\section{SARAN}

Identitas "keterhubungan" yang telah dirumuskan dapat digunakan sebagai titik awal perancangan strategi branding bagi Sidoarjo. Dengan mempertimbangkan aspek-aspek lain seperti ide inti branding, promise of value, dan positioning Sidoarjo.

"Keterhubungan" juga berpotensi sangat besar untuk digunakan sebagai titik awal eksplorasi identitas visual yang mampu mendukung kegiatan city branding Sidoarjo di masa mendatang.

\section{ACKNOWLEDGEMENT}

Ucapan terima kasih ditujukan kepada Dr. Agung Eko Budiwaspada M.Sn., Dr. Naomi Haswanto M.Sn., dan Dr. Alvanov Zpalanzani S.T., M.M., karena telah memberikan arahan dan membuka perspektif baru bagi Penulis.

\section{DAFTAR PUSTAKA}

Anholt, S. 2007. Competitive Identity; The New Brand Management for Nations, Cities, and Regions. Basingstoke. Palgrave Macmillan.

Badan Pusat Statistik Kabupaten Sidoarjo. 2018. Sidoarjo Dalam Angka 2017. Sidoarjo.

Hidayat, A., Bahtiar, R., Hudyastuti, S., dan Safitri, M. D. 2010. Analisis Ekonomi Dampak Semburan Lumpur Panas di Sidoarjo, Jurnal Ekonomi Lingkungan, 14(2), 1-24.

Kuncoro, M. 2004. Otonomi \& Pembangunan Daerah. Jakarta. Penerbit Erlangga.

Govers, R., dan Go, F. 2009. Place Branding: Glocal, Virtual and Physical Identities, Constructed, Imagined, and Experienced. New York. Palgrave Macmillan.

Syahbana, B., Yananda, M. R., Beresaby, R. A., Haryadi, R., dan Salamah, U. 2014. Branding Tempat: Membangun Kota, Kabupaten, dan Provinsi Berbasis Identitas. Jakarta. Makna Informasi. 